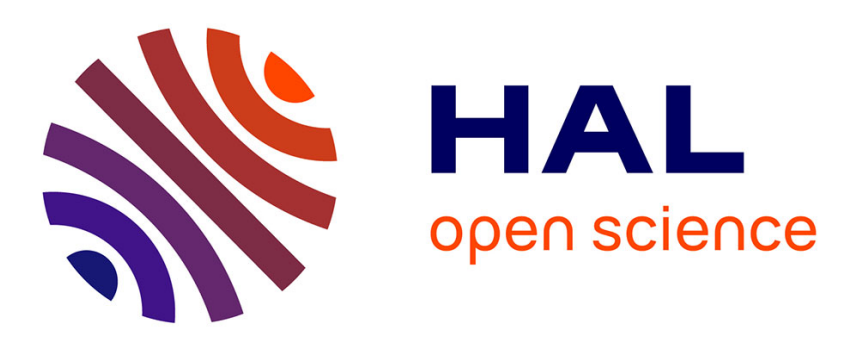

\title{
TamaPeeler: An Interactive Cooking Tool for Children's Dietary Education
}

Yu Ishikawa, Yuko Furudate, Junichi Hoshino

\section{To cite this version:}

Yu Ishikawa, Yuko Furudate, Junichi Hoshino. TamaPeeler: An Interactive Cooking Tool for Children's Dietary Education. 16th International Conference on Entertainment Computing (ICEC), Sep 2017, Tsukuba City, Japan. pp.427-430, 10.1007/978-3-319-66715-7_55 . hal-01771256

\section{HAL Id: hal-01771256 \\ https://hal.inria.fr/hal-01771256}

Submitted on 19 Apr 2018

HAL is a multi-disciplinary open access archive for the deposit and dissemination of scientific research documents, whether they are published or not. The documents may come from teaching and research institutions in France or abroad, or from public or private research centers.
L'archive ouverte pluridisciplinaire HAL, est destinée au dépôt et à la diffusion de documents scientifiques de niveau recherche, publiés ou non, émanant des établissements d'enseignement et de recherche français ou étrangers, des laboratoires publics ou privés. 


\title{
TamaPeeler: An Interactive Cooking Tool for Children's Dietary Education
}

\author{
Yu Ishikawa $^{1 *}$, Yuko Furudate ${ }^{1}$ and Junichi Hoshino ${ }^{1}$ \\ ${ }^{1}$ University of Tsukuba, Graduate school of Systems and Information Engineering, 1-1-1, Ten- \\ nodai, Tsukuba, Ibaraki, Japan \\ \{ishikawa.yu, furudate.yuko\} eentcomp.esys.tsukuba.ac.jp, \\ jhoshinolesys.tsukuba.ac.jp
}

\begin{abstract}
With the change in our diet, importance was placed on dietary education, and various systems for dietary education have been proposed. However, there has been no system that deals cooking tools. This article, therefore, proposes a peeler-type device, 'TamaPeeler', in the hypothesis that touching the food directly and being involved in cooking would raise their interest in food. TamaPeeler detects motions of peeling vegetables, and simultaneously makes various peeling sounds from the wirelessly connected smart phone. As we observed children during its exhibit, we have observed them proactively peeling vegetables, or showing interests in peeling other vegetables, and it was suggested that using an interactive cooking tool can raise the interests of children in food and diet.
\end{abstract}

Keywords: Dietary education, Children, Cooking tool.

\section{Introduction}

As our diet keeps changing, dietary education was considered important in Japan, and in 2005, Basic Act on Food Education that stipulated the basic concepts and items of the measures for food education was established. Its foreword defined food education as an effort to "cultivate knowledge on food and abilities to select them through various experiences, and foster individuals who can practice healthy diet", and importance was placed on the dietary education of children particularly.

Although some systems have been proposed related to food and diet such as a forktype device [1] that makes sounds while eating, and as a system for food education, a fork-type device [2] linked with an application, and a tray-type device [3], as well as projection system [4] have been proposed, but all of these are systems that can be used after food is laid out on the table.

This article proposes "TamaPeeler" - a cooking tool that would motivate children to help in cooking voluntarily (Fig. 1) - in the hypothesis that touching the food directly and being involved in cooking would raise their interest in food. TamaPeeler is a peelertype device that detects motions of peeling vegetables, and coupled with the wirelessly linked smart phone, it makes various sounds. 


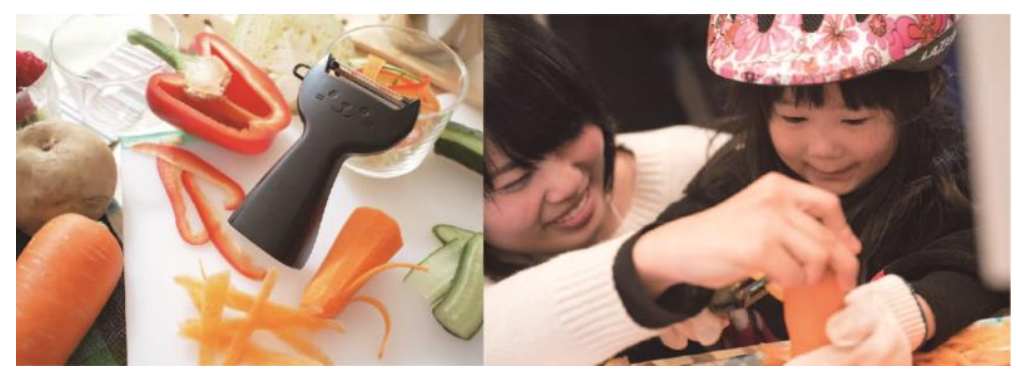

Fig. 1. Overview of TamaPeeler: Left) TamaPeeler, Right) Appearance in experience

\section{System Design}

TamaPeeler is a peeler that has an eye-catching aesthetics for children, and system that makes various sounds in response to the motions of peeling as an entertainment factor so it raises children's interests in cooking itself. It detects: 1) when the peeler touches the vegetable, and 2) the motions of peeling, both of which are called 'soundcreating conditions', and when both conditions were fulfilled simultaneously; the sound will be played on the smart phone.

For judgement of the sound creating conditions, a touch sensor and an acceleration sensor are used in consideration of children's safety. An acceleration sensor alone can be adequate to detect the motions of peeling, but by coupling with a touch sensor, it can prevent from making sounds when children swing the device around with a playful manner.

The peeler also has a function to change some of the sound effects according to the number of times of peeling motions. It counts the number of times that fulfilled soundcreating conditions and after $3 n$-th time $(n=1,2,3 \ldots)$, it will make another kind of sound. As the sound changes after certain times of peeling motions, children could be motivated to keep peeling to hear different sounds.

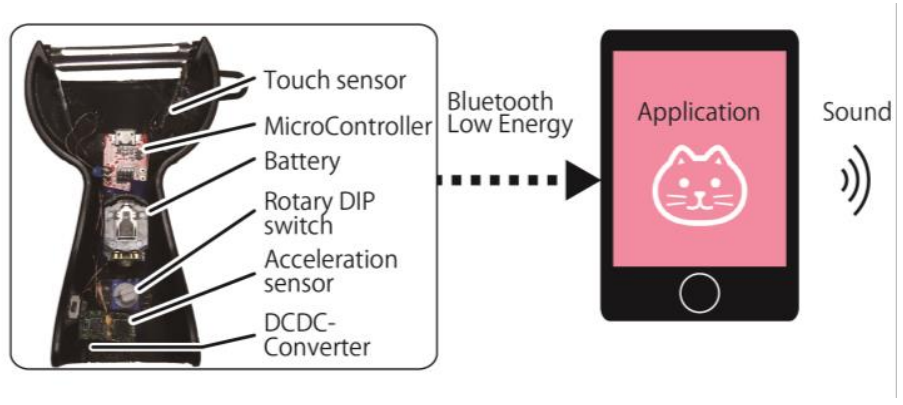

Fig. 2. System Configuration 


\section{Implementation}

System configuration is shown in Fig. 2. To simplify the implementation, the prototype has a rotary DIP switch on the peeler to select kinds of sound, and the sound is played on the wirelessly connected smart phone.

\subsection{Detection of Contact between the Blade and a Vegetable}

Electrodes are attached to the both ends of the blade of the peeler, and they work as a touch sensor mounted. Then, it detects the blade contacts with a vegetable by the change of the electric voltage. As there normally is an allowance for the angle of the blade of a peeler, the terminal of the touch sensor was aligned so it connects at the proper angle when the blade touches the vegetable.

\subsection{Detection of Peeling Motions}

An acceleration sensor is used to detect the peeling motions. In the prototype, based on the most basic peeling motion, the shift of an axis by time are measured and processed with threshold value. The threshold value are tested and set at the value so that it did not make sound when adults swing the peeler around in the air.

\subsection{Playing the Sound}

The sound is played via the specific application on the smart phone's speakers. It has 14 different kinds of sound and part of them is shown in the Table 1. The electric circuit of the peeler and the smart phone are connected wirelessly by an energy-saving close range transmitter, 'Bluetooth Low Energy. The variations of the sounds according to the times of peeling motions are such as, when it is set to play the meows of a cat as in Table 1, No. 1, after 3 n-th time, it switches to bow-wows of a dog.

Table 1. Some sound examples

\begin{tabular}{|r|r|r|}
\hline No. & Name & Onomatopoeia \\
\hline \hline 1 & Cat & meow \\
\hline 2 & Dog & bowwow \\
\hline 3 & Jack-in-the-Box & boing \\
\hline
\end{tabular}

\section{Evaluation}

To verify the applicability of the prototype, we exhibited it, and observed children peeling vegetables with it. The exhibit and the observation were conducted at the Hardware Contest, GUGEN, held in December 2015 in Akihabara.

5 -year old girl was observed to be absorbed in peeling vegetables for long time. When the sound effect is played, she smiled, and looked amused, and she was willing to continue peeling vegetables until the sound changed to a new one. This girl finished her 
'peeling' and went off to see other exhibits, but came back afterwards and wanted to do it again. She was once again absorbed in peeling until her father finally suggested that they should go home. Also, a boy was observed to keep peeling until he could hear all the different kinds of sound. Moreover, it was observed that multiple children wanted to peel other kinds of vegetables voluntarily for the sounds from the smart phone.

The fact that children kept peeling vegetables, and wanted to hear other sounds suggests a possibility that, being able to make sounds by their own motions raised their interests in cooking and positively influenced their voluntary actions. And from their remarks that they wanted to peel other vegetables, it is thought that it raised their interests in other vegetables as well. This suggests that the peeling work they were motivated to try by TamaPeeler triggered their interests, not only in the vegetable they actually touched, but also other related food as well.

\section{Conclusion}

We experimentally created a peeler-type device, TamaPeeler, to promote voluntary participations of children in cooking, and to help food education at home. And at the exhibit of the device, it was observed that, from their motivation to play sounds, children repeatedly peeled the vegetables, and wished to peel other vegetables, wanting to touch many vegetables proactively. From this, it was suggested possible that TamaPeeler can raise children's interests in food through the cooking activities at a kitchen.

In the future, it is our hope that we can compare, by conducting a mid-to-long term experiment, the difference in their interests with or without this device, and study the effects of the sounds as well as the modification of the system and application to other cooking tools besides a peeler.

\section{References}

1. Kadomura, A., Nakamori, R., Tsukada, K., Siio, I.: EaTheremin. In SIGGRAPH Asia 2011 Emerging Technologies, p.7, ACM (2011)

2. Kadomura, A., Li, C. Y., Tsukada, K., Chu, H. H., Siio, I.: Persuasive Technology to Improve Eating Behavior using a Sensor-Embedded Fork. In Proceedings of the 2014 ACM International Joint Conference on Pervasive and Ubiquitous Computing, pp.319-329, ACM (2014)

3. Lo, J. L., Lin, T. Y., Chu, H. H., Chou, H. C., Chen, J. H., Hsu, J. Y. J., Huang, P.: Playful Tray: Adopting Ubicomp and Persuasive Techniques into Play-based Occupational Therapy for Reducing Poor Eating Behavior in Young Children. In International Conference on Ubiquitous Computing, pp.38-55., Springer, Verlag (2007)

4. Mori, M., Kurihara, K., Tsukada, K., Siio, I. Dining Presenter: Augmented Reality system for a dining tabletop. In Proceedings of the 2009 ACM Conference on Ubiquitous Computing Supplemental Publication, UbiComp '09 Supplemental, pp.168-169, ACM (2009) 